\title{
Topical Naloxone Hydrochloride
}

National Cancer Institute

\section{Source}

National Cancer Institute. Topical Naloxone Hydrochloride. NCI Thesaurus. Code C129592.

A topical lotion formulation of the dehydrated, hydrochloride salt form of naloxone, an opiate antagonist, with potential anti-pruritic activity. Upon topical application of the naloxone lotion, naloxone binds to and blocks epidermal mu-opiate receptors. This may suppress or diminish pruritus. 